\title{
Deployments in extreme conditions: Pushing the boundaries of Seaglider capabilities
}

\author{
Bastien Y. Queste, Karen J. Heywood, Jan Kaiser, Gareth A. Lee, \\ Adrian Matthews, Sunke Schmidtko, Christopher Walker-Brown, Stephen W. Woodward \\ School of Environmental Sciences, \\ University of East Anglia, Norwich, UK \\ Email: b.queste@uea.ac.uk
}

\begin{abstract}
Over the last couple of decades, autonomous underwater vehicles have become a powerful tool in the investigation of biological, chemical and physical oceanography. Not only do they complement existing technologies, they open up new avenues of investigation through their specific capabilities. For AUVs to benefit from the same success other long term monitoring platforms have had (moorings, ARGO), it is critical to understand their limits in both monitoring and process studies.

We present results from several Seaglider deployments by the University of East Anglia where Seagliders were pushed to the limit of their abilities. Comparison of missions in extreme conditions at the limits of their depth range $(70$ to $1000 \mathrm{~m})$ and battery life shows a need for tailored survey design and flight parameters in order to maximise mission duration, control over the Seaglider and most efficient science sampling. In particular, we look at post-processing of Seaglider data and present aspects of a new MATLAB toolbox which greatly improves on timestamp correction of Seaglider data by accounting for errors introduced by using a single thread processor.
\end{abstract}

\section{INTRODUCTION}

The past 30 years have seen a tremendous advance in the fields of biological, chemical and physical oceanography. The advent of satellite oceanography combined with improved ship-based capabilities and numerical modelling have provided new insight into the global functioning of the marine ecosystem. This global view allowed us to identify major global issues and led us to further develop ocean models to study and predict interactions between different systems. Today, our knowledge of these issues is limited by a lack of understanding of the finer scale processes. To further refine our understanding and the accuracy of our models we must resolve the meso- and submesoscale features we cannot observe by satellite and how different temporal and spatial scales relate to each other.

This understanding is currently hindered by the disparity of our observations. Carl Wunsch distilled this issue into "having no prospect of a single universal observation system" [1]. Satellites are largely constrained to surface observations, Lagrangian platforms such as floats and drifters provide excellent coverage but lack the necessary resolution to identify mesoand submesoscale features, and mooring or ship based surveys provide the necessary resolution but lack both the spatial and temporal coverage.

More recently, there has been great interest and exponential development in the field of long-range and high endurance gliders. Gliders are autonomous underwater vehicles able to bridge the gap between the different scales of observation and create a synthetic view of a system's functioning. Their mobility allows them to act as virtual moorings or to survey transects up to several thousand kilometres in length, their high endurance allows them to gather observations over the span of seasons, and their modular sensor packages give them the ability to record biological, chemical and physical parameters at very high resolution while providing the information to the user in near real time.

Gliders have repeatedly demonstrated their capabilities in process studies; however, their use in persistent observatories is only just beginning despite [2]-[10]. This is likely due to the remaining uncertainty around the technology. Gliders are a relatively new technology and their limits and abilities are not yet well defined. Gliders need to prove to the scientific community that they are suited to persistent deployments and monitoring observatories by running at low cost without compromising the science.

\section{DEPLOYMENTS}

In this paper, we aim to highlight the strengths and weaknesses of glider platforms by synthesising the issues faced during a series of deployments where gliders were pushed to the limit of their current abilities. The issues encountered were often specific to Seagliders, but many of the same principles apply to other glider-type AUVs. We then review how best to approach Seaglider data and provide information on a toolbox currently in development to aid in the processing of Seaglider data.

In order to fully understand the requirements for prolonged deployments we must identify the troubles which commonly affect deployments. By becoming aware of how and when mission-compromising issues arise, we are able to define strategies which either eliminate or reduce the risk and plan for contingencies.

Although less significant during short deployments, gradually occurring problems have an increasing effect as the duration of a glider's deployment increases. When not properly accounted for, changes such as sensor drift or biofouling may compromise the quality of the results more than the loss of a glider. Table I covers the most common issues affecting glider deployments. Logistical issues can generally be avoided with sufficient forward planning, however they 
TABLE I

COMMONLY OCCURRING ISSUES DURING SEAGLIDER DEPLOYMENTS

\begin{tabular}{|l||c|c|c|}
\hline & Unforeseen / Rapid & Planned / Eventual & Constant / Gradual \\
\hline \hline Mechanical & Equipment failures, breaks and leaks & Battery drain & Sensor drift, wear and tear \\
\hline Logistical & Human error, incorrect calibrations and ballasting & Staff absences, system upgrades & Human error \\
\hline Environmental & Collisions, fishing, theft and wildlife encounters & Poor weather, drop of GPS/satellite signal & Biofouling, varying density ranges \\
\hline
\end{tabular}

TABLE II

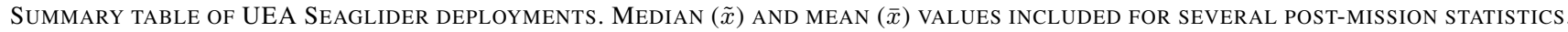
ESTIMATED COMMUNICATION COST PER DIVE INCLUDES PRE-MISSION TESTING OF SEAGLIDERS. * SEE ASPER ET AL. [4] FOR MORE DETAILS ON THE GOVARS MISSION

\begin{tabular}{|c|c|c|c|c|c|c|c|c|c|c|}
\hline Deployment & Glider & $\begin{array}{c}\text { No. of } \\
\text { Dives }\end{array}$ & $\begin{array}{c}\text { Duration } \\
(\mathbf{d a y s})\end{array}$ & $\begin{array}{c}\text { Max } \\
\text { Depth } \\
(\mathbf{m})\end{array}$ & $\begin{array}{c}\text { Max } \sigma \\
\text { difference } \\
\left(\mathbf{k g ~ m}^{-1}\right)\end{array}$ & $\begin{array}{c}\bar{x} \text { AmpHrs } \\
\text { per dive } \\
(\mathbf{1 0} / \mathbf{2 4} \mathbf{~ V )}\end{array}$ & $\begin{array}{c}\bar{x} \text { call } \\
\text { tries }\end{array}$ & $\begin{array}{c}\bar{x} \text { dive \& } \\
\text { surface time } \\
(\mathbf{m i n})\end{array}$ & $\begin{array}{c}\tilde{x} \text { horz. \& } \\
\text { vert. speed } \\
\left(\mathbf{c m} \mathbf{s}^{-1}\right)\end{array}$ & $\begin{array}{c}\text { Comm. cost } \\
\text { per dive (USD) } \\
\text { PSTN/RUDICS }\end{array}$ \\
\hline \hline & 502 & 34 & 2 & 130 & 1.4 & $0.112 / 0.298$ & 1.5 & $28 / 15$ & $35 / 14$ & $\mathrm{~N} / \mathrm{A}$ \\
Scotland Trials & 507 & 18 & 1 & 134 & 1.4 & $0.180 / 0.391$ & 1.5 & $27 / 10$ & $31 / 14$ \\
& 510 & 38 & 2 & 108 & 1.4 & $0.080 / 0.177$ & 1.6 & $30 / 10$ & $36 / 12$ & $\mathrm{~N} / \mathrm{A}$ \\
\hline GOPINA & 510 & 1611 & 113 & 1023 & 2.6 & $0.055 / 0.092$ & 2.0 & $99 / 13$ & $29 / 12$ & $2.98 \mathrm{P}$ \\
\hline North Sea I & 510 & 23 & 1 & 70 & 1.1 & $0.034 / 0.047$ & 2.3 & $12 / 13$ & $37 / 18$ & $19.73 \mathrm{P}$ \\
\& II & 510 & 158 & 4 & 70 & 2.8 & $0.039 / 0.049$ & 2.8 & $15 / 16$ & $32 / 15$ & $9.31 \mathrm{P}$ \\
\hline Tropical DISGO & 537 & 738 & 131 & 1019 & 6.2 & $0.101 / 0.142$ & 2.7 & $242 / 14$ & $25 / 14$ & $4.51 \mathrm{R}$ \\
\hline GENTOO & 522 & 694 & 80 & 1016 & 1.9 & $0.137 / 0.113$ & 3.7 & $177 / 22$ & $35 / 15$ & $2.29 \mathrm{R}$ \\
\hline GOVARS* & 502 & 701 & 59 & 764 & 0.5 & $0.098 / 0.143$ & 1.7 & $107 / 15$ & $34 / 13$ & $3.64 \mathrm{P}$ \\
\hline
\end{tabular}

deserve mention as their likelihood increases with duration and complexity of a mission such as in rotations of multiple gliders required for persistent observatories. Environmental issues can generally not be anticipated and require constant monitoring (AIS services, weather predictions, etc.). Mechanical failures are different in that they have a higher chance of occurring early on in a mission; this provides the opportunity to correct them rapidly. Leaks and faulty equipment can generally be identified immediately, limiting the impact on data collection if proper contingencies are in place. Most deployments therefore tend to be limited by long-term mechanical issues (eg. battery drain) as it is expected gliders and sensors will be sufficiently robust that wear and tear or sensor drift will not compromise the glider's ability to function before it needs to be replaced.

Here we describe the issues encountered during 8 glider deployments by the University of East Anglia (Table II). Some of these missions were very short (on the order of days) and have little in common with persistent deployments but the occurrence of issues during these missions highlights their likelihood in even longer deployments. The deployment of a UEA Seaglider in the Ross Sea (Fig. 1) as part of the GOVARS project will not be discussed as it was previously described by Asper et al. [4]).

\section{A. Seagliders}

All of our deployments used iRobot Seaglider model 1KA units for our ocean observations. Seagliders are autonomous underwater vehicles designed by the University of Washington [11] and recently licensed to iRobot for commercialisation. They have a depth range of 50 to $1000 \mathrm{~m}$ and can perform missions of several months travelling thousands of kilometres. The record for the longest Seaglider deployment is held by Charlie Eriksen, of the University of Washington, with over $5500 \mathrm{~km}$ over 292 days unaided by ocean currents [12]. Seagliders, unlike other AUVs, have no external moving parts. They rely solely on the variable buoyancy device and internal battery pack for motion. By modifying their density, and shifting the battery pack to regulate pitch and roll, they generate lift and forward momentum with the fixed external wings. Their sensor package is fully modular. The Seagliders described in this paper carried an onboard SeaBird CT sail, an Aanderaa 4330F oxygen optode and a Wetlabs Triplet EcoPuck. Seagliders in recent deployments (2011 onwards) were also equipped with a Wildlife Instrument Finmount SPOT-100 tag used as an ARGOS transmitter for emergency location.

The UEA Seagliders use a combination of RUDICS and PSTN communications for piloting and data transfers. The basestation is mirrored every 6 hours and runs on an uninterruptible power supply. The UEA webserver containing Seaglider health status, piloting and science information for pilots and the public is kept on a different server to minimise the risk of compromising the basestation itself. The basestation runs the standard iRobot basestation software versions, complemented by a series of Python and MATLAB scripts developed in-house to render the Seaglider data. This is then displayed on a PHP based web platform using a Google Maps API to display geographic information. Maps and scientific data for all deployments described below are available on the the UEA Seaglider webpage (http://ueaglider.uea.ac.uk). 


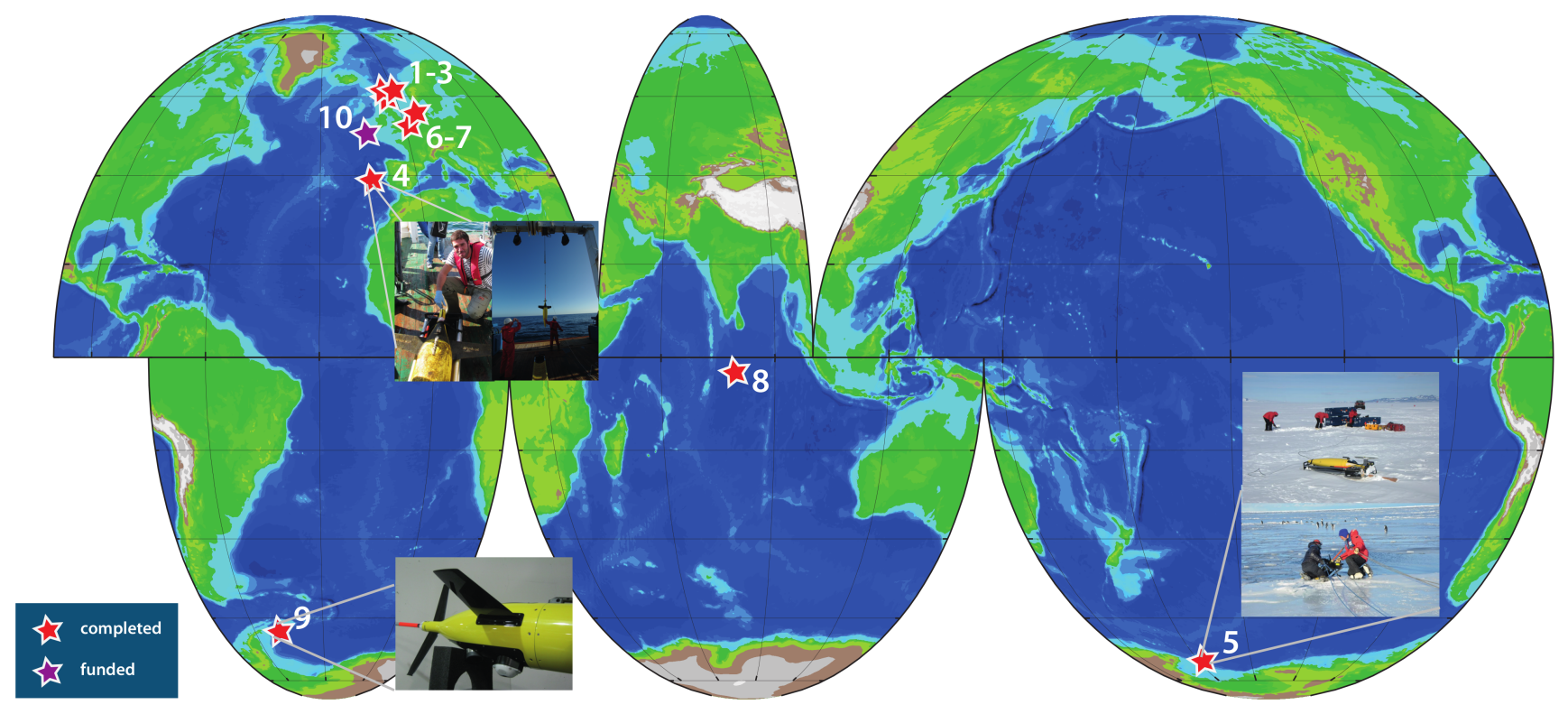

Fig. 1. UEA Seaglider deployments and collaborations. 1-3: Scotland Trials. 4: GOPINA. 5: GOVARS, a collaboration with the Virginia Institute of Marine Science and the University of Washington [4]. 6-7: North Sea. 8: Tropical DISGO. 9: GENTOO, also involving iRobot and the California Institute of Technology. 10: OSMOSIS (scheduled autumn 2012).

\section{B. Scotland Trials}

In March 2010, three Seagliders were deployed in Loch Linnhe, Scotland, to practise piloting and optimising the instruments. We performed a series of short deployments to test how the piloting team could control the Seagliders. On March 22nd we deployed and recovered one Seaglider, simply to test its buoyancy, communication channels, and deployment and recovery techniques. On the following day, we deployed and recovered SG507 and SG510 successfully. Finally, on March 24th we took all three Seagliders to the Lynn of Morvern to undertake an overnight trial. We selected a location commonly used by SAMS to test their AUVs. The location offers waters deeper than $100 \mathrm{~m}$ and little in the way of ship traffic. A single transit route was used regularly to link a local quarry to the mouth of the sea loch. We selected our survey location to be on the opposite side of the sea loch.

During the night, contact was lost with SG507. SG502 and SG510 were safely recovered. All available data were reviewed and it was concluded that SG507 had a collision with a ship heading to the quarry. AIS data available on the internet showed the passage of the Wilson Malm near the Seaglider's last known communication within a twelve minute period. A recovery party was sent after SG507, searching from its last known location using an acoustic transponder. A systematic acoustic survey of the area was undertaken using tidal estimates to determine possible locations of the glider. The combination of strong winds and agitated seas severely hampered the search. The search was continued to no avail in further regions and scanning the beaches around Loch Linnhe.

Despite regular monitoring of ship AIS, collision with the ship was not anticipated. The glider was diving nearly half

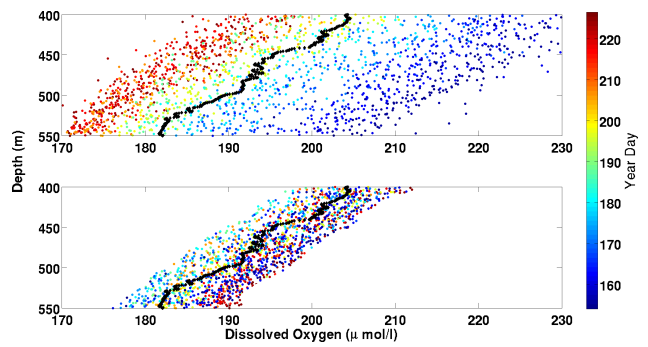

Fig. 2. Pre (top) and post (bottom) sensor drift correction output of the Aanderaa 4330F. A net time-dependent shift is visible indicating gradual sensor drift throughout the mission. The black line represents mean values. Sensors were calibrated against Winkler titrations performed at repeated CAIBEX transect stations.

an hour for every 10 minutes at the surface. Several scenarios were suggested, the most likely being that the gliders antenna, a particularly fragile component, was damaged. Alternatively, it is possible that the Seagliders wings or hull were damaged. We suspect the latter is unlikely as the force required to crack the hull is very large. It is probable the bow wave created by the ship push the glider out of the way, limiting the force of the collision.

\section{GOPINA - Iberian upwelling}

The GOPINA project (Glider observations of productivity in the North Atlantic) aimed to observe productivity in the Iberian Upwelling region. One Seaglider was deployed during the summer of 2010. The glider was deployed from the Mytilus off the coast of Vigo on June $1^{\text {st }} 2010$ where it performed 17 repetitions of a zonal $50 \mathrm{~km}$ transect across the shelf edge. GOPINA was a pilot study involving SG510 aiming to improve our understanding of the mechanisms driving 


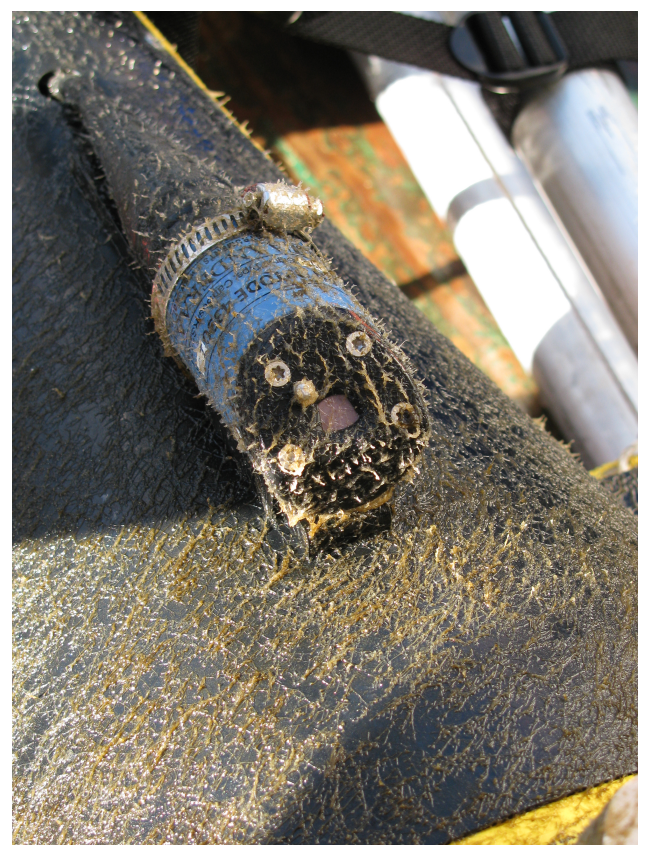

Fig. 3. A thick algal mat covering the Seaglider upon recovery. Growth on the Aanderaa optode may also have contributed to the sensor drift.

production in the Iberian upwelling region by observing the physical, chemical and biological processes off the coast of Spain on scales which are not easily observed by moorings or ships. Here gliders offered an opportunity to observe the water masses in close proximity to the shelf edge during the entire summer season. The primary challenges with this mission were the sharply changing bathymetry along the shelf edge, biofouling, sensor drift, battery life and marine traffic.

The issue of controlling the glider depth was a trade off between simplicity and battery life. Onboard bathymetry was not used due to poorly known bathymetry at the sharp shelf edge and the desire to observe the processes as close as possible to the shelf edge. The two remaining options were frequent changes to the target depth in the command file or the use of the onboard altimeter. The safety of the glider was considered to be the primary goal and the risk of human error too great to rely solely on changing the target depth parameters therefore the onboard altimeter was switched on for the duration of the on-shelf observations. To preserve battery life, the altimeter was switched off beyond the shelf.

The second component of this deployment involved chasing a satellite-observed eddy filament using the glider. This involved crossing four large shipping lanes. The strategy employed was to minimise time spent at the surface despite risking navigational inaccuracies due to the reduced number of GPS fixes and the meridional currents. The glider was flown without surfacing for 10 consecutive dives thereby avoiding the shipping lanes.

The glider was recovered after 147.8 / 88.7 AmpHrs had been consumed out of total of 150 / 100 AmpHrs from the independent 24 and $10 \mathrm{~V}$ batteries respectively. The final battery voltages were 19.6 and $9.7 \mathrm{~V}$ respectively, still above the "safe limits" of 19.0 and 7.9 V. The end of the mission was precipitated by a hardware issue. Due to the partitioning of the memory card, the number of file entries was limited to 4096. When the glider had completed 1358 dives, each dive creating 3 files, and including operating system files, the maximum number of entries was reached. Neither creation or deletion of data were possible any more as they involved the creation of temporary files. Editing of existing files (ie. changing flight and sampling parameters) were still possible but no further scientific data could be recorded. iRobot has since then implemented measures that eliminate this problem.

Over the duration of the mission, the Seaglider's flight became less stable (occasional stalling and asymmetrical dive pattern) and drift of the oxygen sensor output was observed. The first was eventually linked to biofouling covering the entirety of the Seaglider (Fig. 3). Sensor drift of the oxygen optode was observed across the duration of the mission (Fig 2). The drawback of the $4330 \mathrm{~F}$ optode, compared to the standard 4330 optode, is that it is not protected from bleaching by excessive light with an optical isolation layer. Light intensities higher than 15000 lux may cause erroneous readings and prolonged exposure to light will accelerate bleaching of the foil. The advantage is quicker equilibration of the gas permeable sensing foil and therefore a faster response time when observing fluctuations in dissolved oxygen concentrations. Seaglider proximity to the CAIBEX repeat transect stations allowed for progressive cross-calibration to first identify this drift and to determine that it was not an environment change in dissolved oxygen, and secondly correct this drift in the data.

\section{North Sea Hypoxia}

The North Sea mission involved two sequential deployments of SG510 in the central North Sea. This mission aimed at investigating the evolution of mesoscale and submesoscale oxygen processes below the thermocline in the shallow North Sea. The challenge of this region is its relatively shallow depth and the difficulty the glider would have fighting the tidal currents. iRobot recommends a minimum depth of 50 $\mathrm{m}$ for the glider to be able to function properly. During this mission, the Seaglider was operating in waters of $70 \mathrm{~m}$ depth. The North Sea also suffers from very intense use by shipping and hydrocarbon industry.

To maximise the glider's ability to counter the tidal currents, the glider was sent on very steep fast dives. The result was that dives lasted an average of 14.6 minutes diving and 15.9 minutes at the surface (Table II). In such a shallow environment, it is very difficult for the glider to make any headway or be easily controlled. The glider spends half of its time drifting, following dominant winds and surface currents. When it begins a dive, the bottom and top $10 \mathrm{~m}$ are used for adjusting pitch and roll and the glider makes no significant headway. Nevertheless, the glider was able to maintain its position, acting as a "virtual mooring", when currents were against the glider's direction. When currents pushed the glider in its desired direction, it was able to cover long distance rapidly. However, obtaining regular 
spatial coverage or following a clear transect line, to avoid oil platform exclusion zones for example, was very difficult. These steep, fast dives require large changes in buoyancy which drain the $24 \mathrm{~V}$ battery rapidly. To limit this issue, iRobot now make available an enhanced buoyancy engine, specifically designed to increase efficiency in shallow waters. This boost pump does not function at depth (below $120 \mathrm{~m}$ ), but is both quicker and more efficient in shallow waters.

As a consequence of the faster diving speeds to counter currents, there was a need for fast sensor sampling. As the glider travelled at vertical velocities of $0.17 \mathrm{~m} \mathrm{~s}^{-1}$, it was necessary to sample at the maximum rate $(0.2 \mathrm{~Hz})$ to properly resolve the features we wished to observe. The combination of very large buoyancy changes to drive the glider's motion and maximum sampling rate led to a large energy consumption, despite the presence of the enhanced buoyancy engine. Typical consumption rates were of the order of $0.039 \mathrm{AmpHrs}$ and 0.049 AmpHrs per dive of the 10 and $24 \mathrm{~V}$ batteries respectively.

The second deployment was terminated prematurely due to an error in the formatting of the memory card. Unlike the Vigo mission where an unusually large number of dives were performed, here the memory card had been incorrectly formatted thereby limiting the possible number of files to 512. The glider was placed in "virtual mooring" mode and recovered at the earliest convenience. As no further science could be recorded, there was no reason to leave the glider in a vulnerable position around oil and gas platforms or ships.

\section{E. Tropical DISGO - Indian Ocean}

A Seaglider was deployed from September 14th 2011 to January 23rd 2012 in the Indian Ocean where it performed 10 repeats of a meridional transect between $3^{\circ} \mathrm{S}$ to $4^{\circ} \mathrm{S}$ along $78^{\circ} 50^{\prime} \mathrm{E}$. The Seaglider was deployed and recovered from R/V Roger Revelle from Scripps Institution of Oceanography, San Diego. This deployment was a component of the CINDY2011/DYNAMO project. The main objective was to investigate the atmospheric and oceanic mechanisms which trigger the Madden-Julian Oscillation (the principal mode of tropical climate variability in the Indian Ocean). The mission had two main objectives: to obtain a detailed view of the diurnal cycles in the vertical structure of the surface layers and to measure the structure of oceanic equatorial waves implicated in the generation of some Madden-Julian Oscillation events.

During deployment the main concern was battery life and balancing a long (4 month) deployment against getting sufficient data. The main issue that affected this, and could have been avoided, was that the glider was very badly trimmed for the density profile in the tropics. The Seaglider had to cope with a very strong pycnocline and very large density difference between the surface and $1000 \mathrm{~m}$ (Table II). It took over a month to fully trim the Seaglider's flight to an efficient level. To maximise battery life, the Seaglider's flight was adjusted for minimal necessary buoyancy and shallowest glide angle achievable. One unanticipated consequence of pushing the Seaglider's flight to the stalling limit was that this meant the

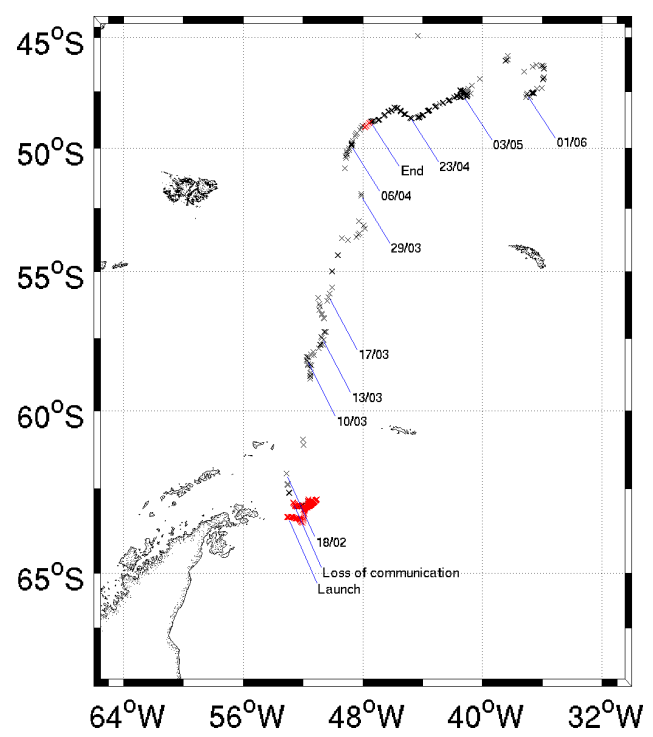

Fig. 4. Map of Seaglider GPS positions (red) and ARGOS positions (black) with significant dates during the GENTOO mission.

flow past the conductivity sensor on the climb phase was too slow to produce accurate conductivity data.

Having pushed the glider's flight to its limit in order to maximise the $24 \mathrm{~V}$ battery life, the $10 \mathrm{~V}$ was now depleting faster. In order to regulate the consumption of the $10 \mathrm{~V}$ battery, changes had to be made to the sensor sampling regime. As the mission mainly aimed to obtain temperature and conductivity data, the Aanderaa optode and the Wetlabs puck were activated for a few dives every week to track longer term variations whereas the CT sail recorded continuously. To further reduce consumption, the Wetlabs optical sensor sampled once every 15 seconds at most. The optode sampled every 5 seconds in the upper water column $(0-100 \mathrm{~m}), 15$ seconds in mid water $(100-300 \mathrm{~m})$ and was switched off at depth. The CT sail recorded every 5 seconds between 0 and $300 \mathrm{~m}$, and every 15 seconds below $300 \mathrm{~m}$. By limiting the data recorded, battery consumption from communications and sensor sampling were both reduced, bringing the consumption rate of the $10 \mathrm{~V}$ battery to a manageable level.

\section{F. GENTOO - Weddell Sea}

We deployed three Seagliders in the western Weddell Sea, along the Antarctic Peninsula, in collaboration with the California Institute of Technology and iRobot. The mission investigated the physical and biological processes associated with the Antarctic Slope Current. The UEA glider (SG522) was deployed on January 23rd 2012 to survey the shelf edge. Iridium communication was lost with the glider on February 14th 2012. Continuous tag signals were obtained until April 14th; following this date, fixes became irregular, often several days apart. Following a 58 day absence of communications, the Seaglider entered recovery due to low $10 \mathrm{~V}$ battery voltage. The battery lasted enough for the transfer of 8 dives before dropping below the threshold necessary to power the Tattletale 8 processor. ARGOS communications continued during this 
period and a recovery mission was initiated. The SPOT tag ceased transmitting before the recovery ship reached the glider's location.

It was later concluded the glider's disappearance was due to a series of conflicting commands which led to the Seaglider diving continuously without attempting to communicate with the basestation. It continued on its original northward heading, crossing the Weddell Sea, the Antarctic Circumpolar Current and entering the Argentine Basin (Fig. 4). Despite not being piloted, the Seaglider was able to cross an area of very rapid currents and continue north by nearly $15^{\circ}$.

Although the ARGOS tag provided satellite fixes once the Seaglider stopped communicating, their use in the recovery was limited. Location fixes were usually only available 4 hours after the satellite obtained the fix. The tag was programmed to transmit only 150 times per day starting at 0:00 GMT to conserve battery life. This meant that once the glider went into recovery, all its transmissions were done during hours of darkness. The tag also did not supply fixes continuously during the mission. The cause of this is unknown but is most likely due to the effects of sea state, salt creep, and the position of the tag on the antenna. It is also possible the glider may have been in a satellite "black spot".

\section{DEALING With DATA}

Due to the relatively recent commercialisation of Seagliders and commercial decisions from the manufacturer, there are very few tools for the correction and calibration of Seaglider data. Most commercial CTD packages come with an intricate software suite which corrects for various sensor and thermal lags, applies corrections, smooths and despikes the data and provides a binned final product. iRobot provides a set of MATLAB scripts to its customers that do basic checks of glider flight and science sensor functionality but leaves it to the customer to develop in-depth data analysis tools specific to their research and publishing needs.

To this end, we are in the process of developing a toolbox to add in the processing, both operationally and post-mission, of Seaglider data. We apply a new corrections scheme for scientific data sampled by Seagliders. The Seaglider has a single thread Tattletail 8 processor as sole CPU. Thus all guidance and control as well as scientific operations have to be handled successively. Since the guidance and control takes priority over scientific sampling, significant delays may occur between timestamping and scientific sampling. Furthermore, with increasing sensor payloads, there is a tendency to increase the number of parameters being sampled with additional sensors. Each sensor has an average wake-up and response time of one to three seconds. Cumulatively, these add up to differences of up to 12 seconds between the first and last sensor records. Since all sensor samples from a single round of measurements are associated to a single timestamp, there is a systematic bias in the data. As the timestamp is the first element to be recorded, data are sampled deeper than the timestamp on the downcast and shallower on the upcast. The depth anomaly created is of the order of $2 \mathrm{~m}$ with a vertical

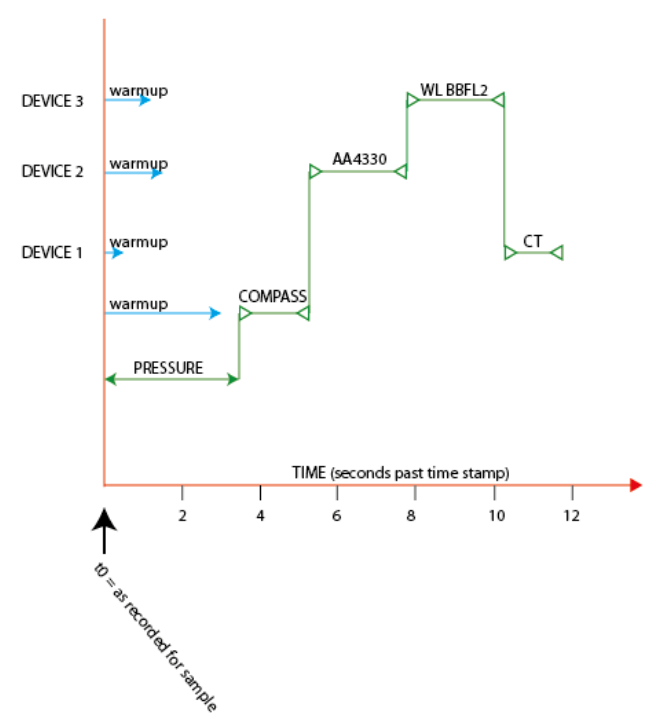

Fig. 5. Successive sampling of devices with associated timelags and warm-up delays for a standard sensor payload on the Seaglider 1KA.

speeds of $15 \mathrm{~cm} \mathrm{~s}^{-1}$, thus the difference between the up and down casts can reach $4 \mathrm{~m}$ or more for last triggered sensor.

This lag is not accounted for in either the Seaglider software or the data processing packages provided. The developers have suggested shifting the up and down profiles by 20 $\mathrm{cm}$ and assuming constant vertical speeds on the up and down casts. A formal correction is complicated by irregular sampling patterns. The sensor sampling is fully configurable with sensors sampling at different frequencies, the guidance and control routines also activate at a different frequency. To further complicate matters, this is not even regular on a single dive as frequencies may be programmed to be depth dependent. The correction we currently apply analyses each sample to determine which sensors operated and in which order, using information provided by iRobot, and uses a sensor and mission specific look-up table to correct for the average delay for each sensor (Fig. 5). We are confident that we address the associated sampling bias to a degree that is sufficient for errors to be smaller than measurement noise in pressure. After addressing this sampling bias, we apply further quality control procedures as recommended by the EGO initiative (part of the GROOM European design study), as well as time and thermal lag corrections as described by Garau et al. [13].

\section{Summary}

Seagliders remain a fairly new technology. International collaboration between glider groups has become critical to ensure we develop the necessary understanding of glider strengths and weaknesses to push their capabilities beyond what is currently possible. Every new deployment provides a new set of experiences and problems. The next deployment the University of East Anglia will be involved in is a year-long multi-glider deployment, involving three rotations to ensure continuous coverage of the Porcupine Abyssal Plain. This project, dubbed OSMOSIS (Ocean Surface Mixing, Ocean Sub-mesoscale 
Interaction Study) will monitor upper ocean processes during a full seasonal cycle from September 2012 to September 2013. Full details are available on http://ueaglider.uea.ac.uk.

\section{ACKNOWLEDGMENT}

The authors would like to thank the crew, officers and scientists of the BIO Mytilus, the RV CEFAS Endeavour, the RV Roger Revelle, and the RRS James Clark Ross. We are also very grateful for the help and support provided by iRobot, specifically Elizabeth Creed and the whole of the Maritime Support team, and members of the University of Washington, Fritz Stahr, Craig Lee, Jason Gobat and Geoffrey Shilling. We also thank the staff at the CSIC (Spain), Des Barton, SAMS (Scotland), Toby Sherwin and Estelle Dumont, and the entire UEA Seaglider team. These project were funded through a Natural Environment Research Council (NERC) CASE studenship with CEFAS and the UEA, through the NERC grant NE/H012532/1, GENTOO NERC grant NE/H01439X/1 and GROOM infrastructure design study for the EU Framework 7 Programme. We are grateful for additional funding from CEFAS, and thank the UEA Science Faculty for the funding to purchase the 4 Seagliders.

\section{REFERENCES}

[1] C. Wunsch, "Observational Network Design for Climate," Proceedings of OceanObs'09: Sustained Ocean Observations and Information for Society, no. 1, pp. 440-449, Dec. 2010. [Online]. Available: http://www.oceanobs09.net/proceedings/pp/pp41

[2] D. Nicholson, S. Emerson, and C. Eriksen, "Net community production in the deep euphotic zone of the subtropical North Pacific gyre from glider surveys," Limnology and Oceanography, vol. 53, no. 5, 2008. [Online]. Available: http://www.jstor.org/stable/10.2307/40058380

[3] N. Briggs, M. J. Perry, I. Cetinić, C. Lee, E. D'Asaro, A. M. Gray, and E. Rehm, "High-resolution observations of aggregate flux during a sub-polar North Atlantic spring bloom," Deep Sea Research Part I: Oceanographic Research Papers, vol. 58, no. 10, pp. 1031-1039, Oct. 2011. [Online]. Available: http://linkinghub.elsevier.com/retrieve/pii/S0967063711001361

[4] V. Asper, W. O. Smith Jr, C. Lee, J. Gobat, K. J. Heywood, B. Y. Queste, and M. Dinniman, "Using gliders to study a phytoplankton bloom in the Ross Sea, Antarctica," in OCEANS 2011, 2011, pp. 1-7. [Online]. Available: http://ieeexplore.ieee.org/xpls/abs_all.jsp?arnumber=6107082

[5] M. J. Perry, B. S. Sackmann, C. Eriksen, and C. M. Lee, "Seaglider observations of blooms and subsurface chlorophyll maxima off the Washington coast," Limnology and Oceanography Special Issue on Autonomous and Lagrangian Platforms and Sensors (ALPS), vol. 53, no. 5 part 2, pp. 2169-2179, 2008.

[6] E. Frajka-Williams, P. B. Rhines, and C. Eriksen, "Physical controls and mesoscale variability in the Labrador Sea spring phytoplankton bloom observed by Seaglider," Deep Sea Research Part I: Oceanographic Research Papers, vol. 56, no. 12, pp. 2144-2161, Dec. 2009. [Online]. Available: http://linkinghub.elsevier.com/retrieve/pii/S0967063709001642

[7] D. Nicholson, S. Emerson, and C. Eriksen, "Net community production in the deep euphotic zone of the subtropical North Pacific gyre from glider surveys," Applied Physics, vol. 53, pp. 2226-2236, 2008.

[8] M. B. Alkire, E. DAsaro, C. Lee, M. Jane Perry, A. Gray, I. Cetinić, N. Briggs, E. Rehm, E. Kallin, J. Kaiser, and A. González-Posada, "Estimates of net community production and export using high-resolution, Lagrangian measurements of $\mathrm{O} 2$, NO3, and $\mathrm{POC}$ through the evolution of a spring diatom bloom in the North Atlantic," Deep Sea Research Part I: Oceanographic Research Papers, no. 3, Feb. 2012. [Online]. Available: http://linkinghub.elsevier.com/retrieve/pii/S0967063712000313
[9] B. S. Sackmann, M. J. Perry, and C. Eriksen, "Seaglider observations of variability in daytime fluorescence quenching of chlorophyll-a in Northeastern Pacific coastal waters," Biogeosciences, vol. 5, pp. 2839$2865,2008$.

[10] D. L. Rudnick, R. E. Davis, C. Eriksen, D. M. Fratantoni, and M. J. Perry, "Underwater gliders for ocean research," Marine Technology Society Journal, vol. 38, pp. 73-84, 2004.

[11] C. Eriksen, T. J. Osse, R. D. Light, T. Wen, T. W Lehman, P. L. Sabin, J. W. Ballard, and A. M. Chiodi, "Seaglider: a long-range autonomous underwater vehicle for oceanographic research," IEEE Journal of Oceanic Engineering, vol. 26, no. 4, pp. 424-436, 2001. [Online]. Available: http://ieeexplore.ieee.org/lpdocs/epic03/wrapper.htm?arnumber=972073

[12] University of Washington, "Seaglider Fabrication Center," 2012. [Online]. Available: http://www.seaglider.washington.edu/

[13] B. Garau, S. Ruiz, W. G. Zhang, A. Pascual, E. Heslop, J. Kerfoot, and J. Tintoré, "Thermal Lag Correction on Slocum CTD Glider Data," Journal of Atmospheric and Oceanic Technology, vol. 28, no. 9, pp. 1065-1071, Sep. 2011. [Online]. Available: http://journals.ametsoc.org/doi/abs/10.1175/JTECH-D-10-05030.1 